\title{
The Trade-Wind Inversion as a Transoceanic Duct
}

\author{
M. Katzin, H. Pezzner, B. Y.-C. Koo, J. V. Larson, and J. C. Katzin
}

(December 21, 1959)

\begin{abstract}
Radiosonde data for stations in the South Atlantic trade-wind belt are analyzed to determine the potentialities of the trade-wind inversion as an elevated duct for transoceanic radio transmission. These were supplemented by refractometer soundings made by an aircraft during the latter part of 1958. These records indicate that a duct is present in tha majority of the cases. Since it is known that the radiosonde underestimates ducting because of its slow response, it is concluded that a duct is present practically all the time. On the basis of the data analyzed, an experiment with two aircraft is suggested to test the propagation potentialities of this mechanism. A frequency of around 200 megacycles per second appears to be a gcod choice for an initial experiment.
\end{abstract}

\section{Introduction}

This paper describes the investigation of a conjecture that it may be possible to communicate across the oceans by means of vhf or uhf waves in the elevated ducts created by the trade-wind inversions. This conjecture developed out of the following evidence:

In World War II, record radar ranges were obtained on a 200-Mc radar at Bombay during the season of the northeast monsoon. Frequently the entire coast of Arabia would be painted on the radar PPI, and ranges up to about 1,700 miles were obtained. The meteorological situation, as reported by Durst [1], ${ }^{2}$ results from hot dry air moving down from the Asian continent and overlying cooler moist air above the Arabian Sea. The combination of the two kinds of air produces a temperature inversion. At the level of the inversion, a temperature increase and a moisture decrease with increasing height occur. These both effect a decrease of refractive index with height, with the result that a strong elevated duct is created. Since a radar range of 1,700 miles represents a two-way traverse, the total range of transmission was up to 3,400 miles.

In a preliminary study of meteorological data for the South Atlantic region between Ascension Island and the Brazilian coast, a similarity of the conditions in the trade-wind inversion to those which were effective in producing the record ranges over the Arabian Sea became apparent. Since the trade inversion extends between the continents, or islands contiguous thereto, it appeared that here might be a mechanism capable of propagating radio waves clear across the oceans with low attenuation, and thus requiring relatively little power to effect communications. Because of the persistence of the trade winds, which blow virtually continuously through the year, is also appeared that this mechanism might be a reliable one.

${ }^{1}$ Contribution from Electromagnetic Research Corp., Washington, D.C. This work was supported by Air Research and Development Command, U.S. Air Force.

${ }_{2}^{2}$ Figures in brackets indicate the literature references at the end of this paper.
In order to determine the possible success of an experimental program, it was decided to analyze existing radiosonde records, which were the only data then available for regions of interest.

It was realized from the outset that radiosonde data had great shortcomings for use in revealing the existence of ducts. This is due principally to the lag of the temperature and humidity elements in comparison to the rate of ascent of the ballon. It was felt, however, that the indications obtained from the radiosonde would be pessimistic, so that a favorable indication perhaps should be interpreted as a strong probability.

Among the various trade-wind regions, the region of the South Atlantic trade was singled out for study, especially the portion between Ascension Island and the Brazilian coast.

In this paper, the results of the analysis of available radiosonde data are summarized. Because of the favorable nature of these results, arrangements were made to take airborne refractometer measurements of the refractive index distribution through the inversion region. These measurements were made during a two-week period in November and December 1958 by Dr. R. M. Cunningham of the Air Force Cambridge Research Center in bis Airborne Cloud Physics Laboratory. In addition, the regular daily schedule of radiosonde measurements at Fernando de Noronha and Ascension Island were stepped up to four per day during this period for comparison with the refractometer soundings, as well as to investigate a possible diurnal variation in inversion characteristics. The results of these additional measurements are also summarized here.

\section{Characteristics of the Trade Inversion}

A brief review of the known characteristics of the trade-wind inversion will be presented as a background against which to view the results obtained from the present study. Present knowledge of these characteristics is due largely to the classical papers of von Ficker [2] and Schnapauff [3], which are sum- 
marized in Riehl's [4] book. We shall be concerned here entirely with the Atlantic trade winds, especially those of the South Atlantic.

It is believed that the trade-wind inversion is due to dry air descending from high levels at the eastern ends of subtropical high-pressure regions. This subsiding air meets a current of moist and cooler air above the oceans. The warm air above forms a stable blanket over the cooler air below which inhibits vertical motion and large-scale mixing of the two streams of air. An inversion thus forms at the level where these streams meet.

According to von Ficker [2], the height of the trade inversion is subject to day-to-day and seasonal fluctuations. In the South Atlantic trade, the inversion rises as one proceeds westward from the African coast. The temperature rise, or "strength" of the inversion, decreases to the westward and equatorward. The most intense change in relative humidity within the inversion also is associated with the lowest inversion heights, and decreases westward and equatorward.

From the height, temperature rise, and humidity decrease characteristics, von Ficker's data indicate that the inversion begins at the African coast at a low height and is very intense. As one progresses westward, there is at first a relatively rapid rise in height, accompanied by a decrease in the amount of temperature and humidity change. These changes in height and strength of the inversion flatten off about one-third of the way across the ocean, after which the height remains fairly constant and the temperature and humidity changes decrease slowly with distance.

\section{Raw Data and Method of Analysis}

For the present study, the principal source of information was radiosonde data which, for the most part, consisted of tabulations of temperature and relative humidity at so-called "significant" and "mandatory" levels. From these values the modified index, $M$, was computed from

$$
M=N+0.157 h,
$$

where $h$ is the height in meters, and $N$, the refractivity, is calculated from the relation (Smith and Weintraub [5])

$$
N=\frac{77.6}{T}\left(p+4,810 \frac{e}{T}\right)
$$

in which $T$ is the absolute temperature, $p$ is the atmospheric pressure in millibars, and $e$ the partial pressure of water vapor in millibars.

An example of the results of a sounding is shown in figure 1 . The curve (a) is an $M$-curve for a nighttime sounding taken at Ascension Island on November 7,1944 . From the $M$-curve, one deduces that an elevated duct with a $\Delta M$, or "strength," of 8 units is present between the heights 1,400 to 1,690 $\mathrm{m}$. This sounding was specifically selected to show the presence of a duct.

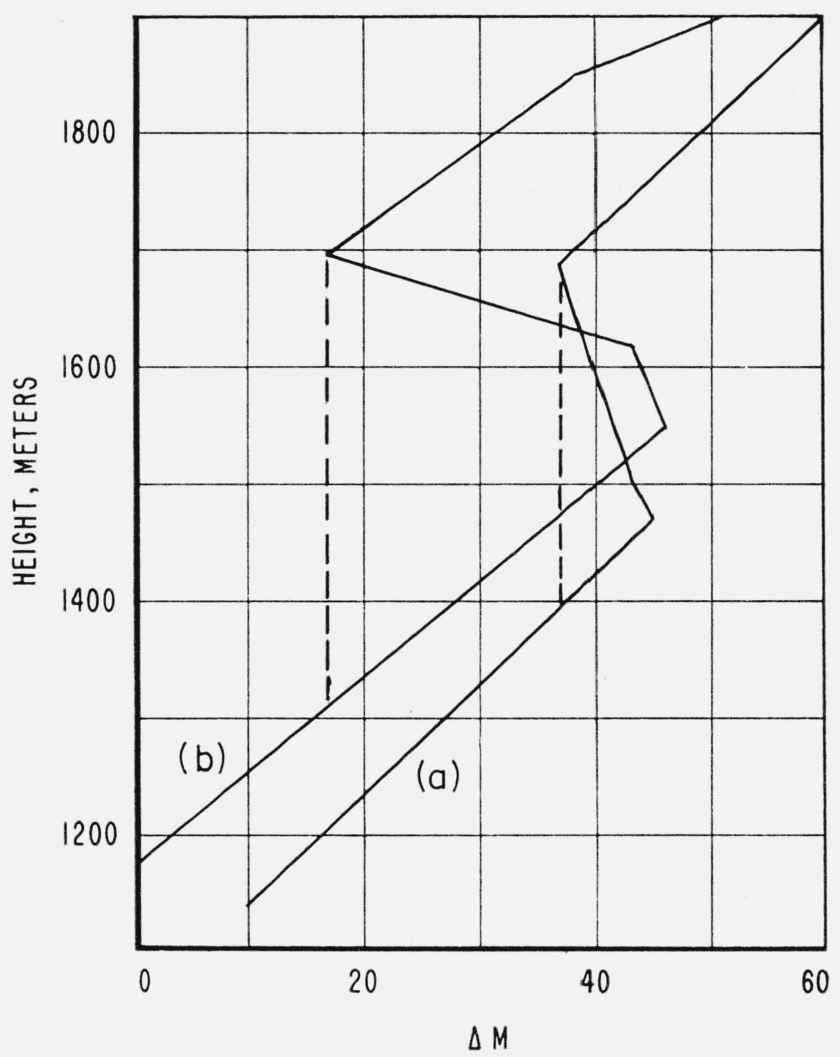

FIGURE 1. M-curve calculated from radiosonde significantlevel observations, Ascension Island.

(a) Sounding of November 7, 1944, 2340 GCT; (b) sounding of November 15, 1957, 1145 GCT.

Because of the large amount of data, the following procedure was adopted for the bulk of the analysis. From the significant-level tabulations, the indicated levels of the bottom and top of the inversion could be spotted easily. From the values of pressure, temperature, and relative humidity corresponding to these and any intervening levels, $\mathcal{N}$ was computed. Chronological graphs were then prepared, showing the heights of the top and bottom of the inversion, the decrease of $N$ between these heights, and surface wind speed and direction. Since some stations took one sounding per day, while others took two, the data were divided into day and night groupings for the latter cases. Some of these graphs are given in the accompanying figures, which will be discussed in section 4.

Dr. Cunningham's Airborne Cloud Physics Laboratory was equipped with extensive instrumentation for measurement of air and cloud particle properties. The data of immediate interest to the present study were the records of temperature and refractive index, especially the latter. The refractive index measurements were made with a microwave refractometer of the Crain type. A number of ancillary data were recorded, such as altitude, air speed, time markers, markers to indicate entry into and emergence from cloud, as well as cloud particle data. The profiles 
through the inversion region were taken at a rate of ascent or descent of 500 to $1000 \mathrm{ft} / \mathrm{min}$. Also a few horizontal runs were made near the cloud tops to explore the wavy nature of the base of the inversion.

\section{Results and Discussion}

\subsection{Standard Radiosonde Summaries}

The stations for which radiosonde summaries were analyzed are listed in table 1.

TABLE 1

\begin{tabular}{|c|c|}
\hline Station & Location \\
\hline $\begin{array}{l}\text { Ascension I } \\
\text { Fernando de Noronha I } \\
\text { Luanda, Angola, P.W.A } \\
\text { Natal, Brazil } \\
\text { Recife, Brazil }\end{array}$ & $\begin{array}{l}\text { 8. } 0^{\circ} \mathrm{S}, 14.6^{\circ} \mathrm{W} \\
\text { 3. } 8^{\circ} \mathrm{S}, 32.4^{\circ} \mathrm{W} \\
\text { 8. } 9^{\circ} \mathrm{S}, 13.0^{\circ} \mathrm{E} \\
5.8^{\circ} \mathrm{S}, 35.3^{\circ} \mathrm{W} \\
8.1^{\circ} \mathrm{S}, 34.9^{\circ} \mathrm{W}\end{array}$ \\
\hline
\end{tabular}

Figure 2 is a chronological plot of the night soundings at Ascension Island for 1944. The points plotted for the individual days have been connected by straight lines. For some days data were missing, either due to no data or to no inversion. To differentiate between these two reasons for no data, dots were entered at the bottom of the graph, a single dot for no inversion and a double dot for no data. The instances of "no inversion" were quite rare.

A rather large day-to-day fluctuation in height and in $\Delta N$ is evident. In spite of this, a gradual seasonal trend in the heights can be discerned. Similar characteristics were found to exist in the daytime data, and in the data for 1945 .
In order to bring out the seasonal characteristics clearly, 30-day running averages were computed for the heights and $\Delta N$ from the data of figure 2. These are plotted in figure 3. This brings out quite strikingly the seasonal variation, the average height of the lower boundary of the inversion increasing from about $1,300 \mathrm{~m}$ in summer (January) to about $1,800 \mathrm{~m}$ in winter (July). The thickness of the inversion shows only little variation between about 300 and $400 \mathrm{~m}$, since the top and bottom move together fairly closely, even in detail. It must be remembered, however, that these are running averages of the data. In spite of this, the closeness with which the two curves follow each other is quite remarkable. From this, one is led to conclude that, by and large, whatever causes the dav-to-dav variations in height effects a bodily transport of the inversion layer. The average decrease of $N$ in figure 3 varies between about 25 and 40 without, however, showing a marked seasonal correlation.

Data for the stations on or near the Brazilian coast varied considerably in quality. In most instances there are long gaps in the data, which make it difficult to deduce trends or averages. The data from the stations at Natal and Recife show evidences of several inversions existing at times.

As mentioned above in section 2, the sounding for curve (a) of figure 1 was specifically selected to show the presence of a duct. On that occasion a large decrease in $N$ occurred over a moderate height interval, so that the first term on the right of eq (1) gave a larger decrease than the increase due to the second term containing $h$. Thus $M$ decreased over the height interval between the two significant levels recorded. In the majority of cases, however, the

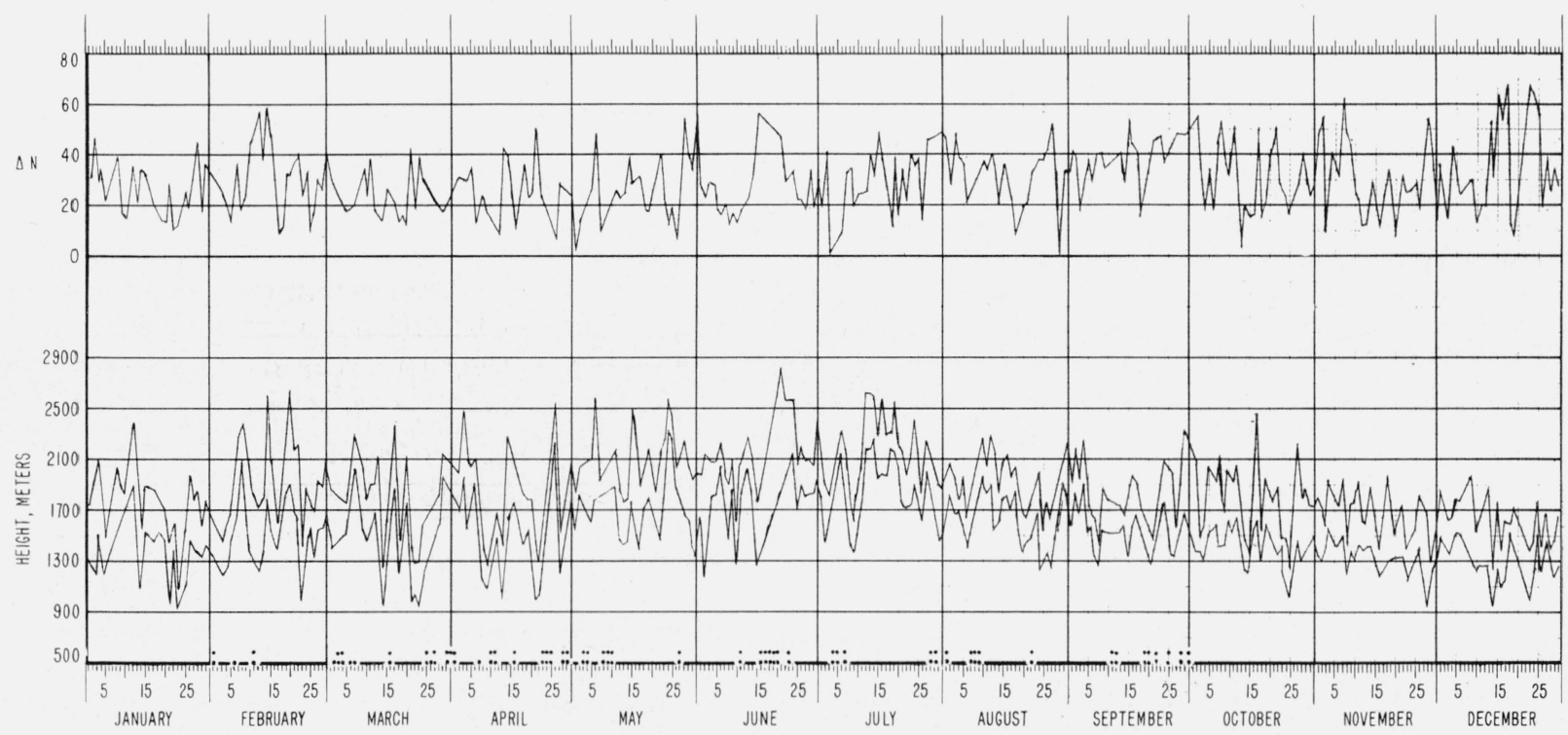

Figure 2. Chronological plots of heights at top and bottom of inversion, decrease of $N$ through inversion $(\Delta N)$, and surface wind speed and direction.

Ascension Island, midnight soundings, 1944. Double dots at bottom denote "no data," single dots, "no inversion." 


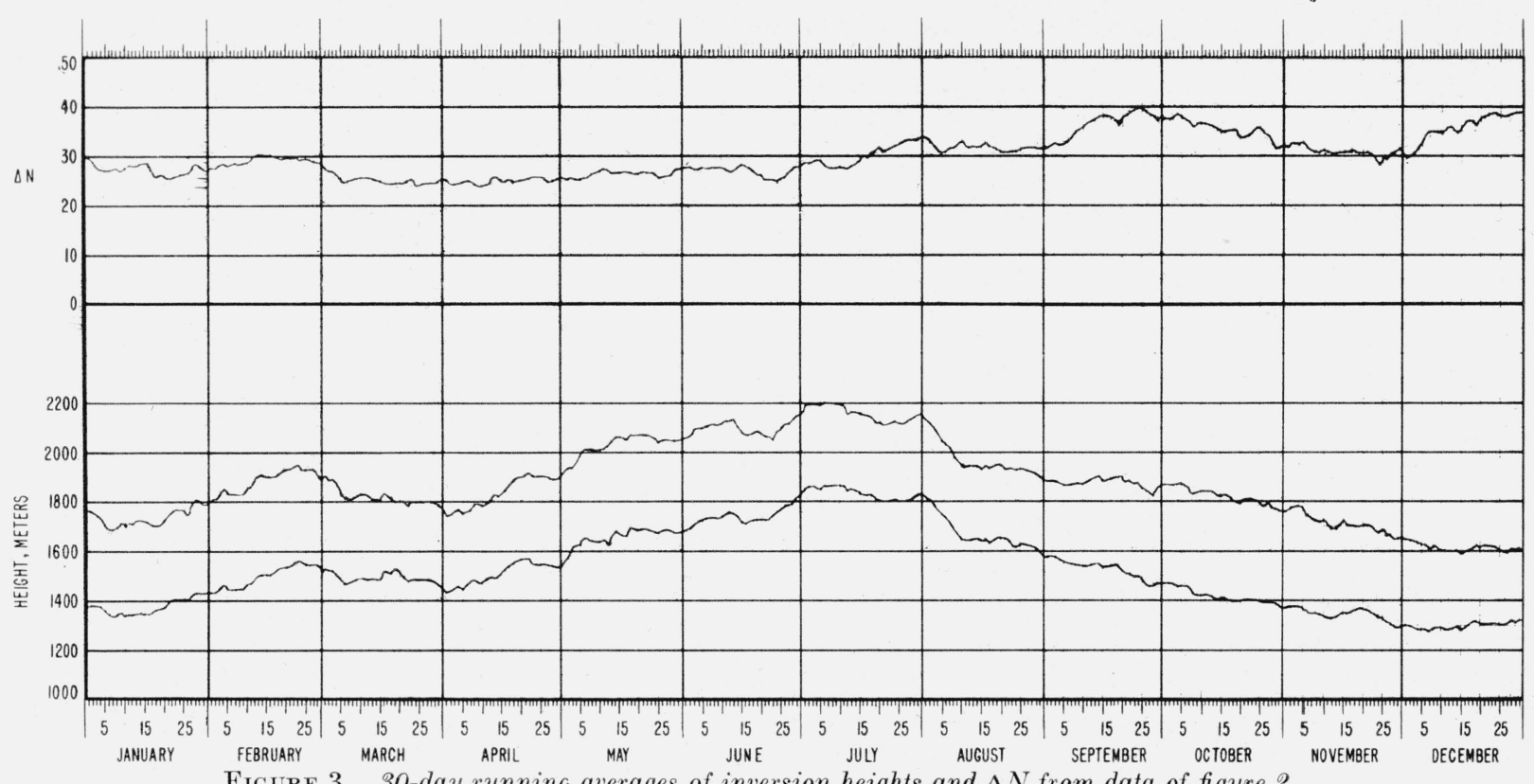

FigurE 3. 30-day running averages of inversion heights and $\Delta N$ from data of figure 2.

1944 and 1945 data from Ascension Island indicated no duct because the decrease in $N$ took place over a height interval so large that the increase in the second term in eq (1) was larger than the decrease in $N$

The data for Ascension Island for the latter part of 1957, shown in figure 4, are striking in comparison with the data in figure 2 . It is evident immediately that the thickness of the inversion is much less in the later data, by a factor of two or more. Furthermore, the $\Delta N$ 's run to higher values, also by a factor of about two. This has a profound effect on the trapping capabilities of the inversion. Curve (b) in figure 1 shows a plot of a selected sounding similar to that shown in curve (a). The $M$-curve shows a duct extending from 1,115 to $1,500 \mathrm{~m}$, with a strength of $29 M$-units. The same type of change is evident in the character of the later data for the Brazilian stations. The later data indicate that a duct is present in a majority of the soundings, as will be shown below.

The rather sharp change in inversion characteristics as revealed by the 1944 and 1957 data suggests that a change in the speed of response of the radiosonde instrument used took place between those dates (presumably the replacement of the hair hyorometer by the lithium chloride strip). This matter is related to the basic question regarding the reliability with which duct characteristics can be determined from radiosonde data. Andre [6] has discussed the limitations of radiosonde data for use in refractive index computations. He concluded that the modern radiosonde registers only those ducts which have scales of hundreds of feet or more, and that these are shown as being weaker, thicker, and higher than they actually are.
Table 2 shows the percentage of soundings which indicated ducts for the stations listed in table 1 . It can be seen from table 2 that more recent measure-

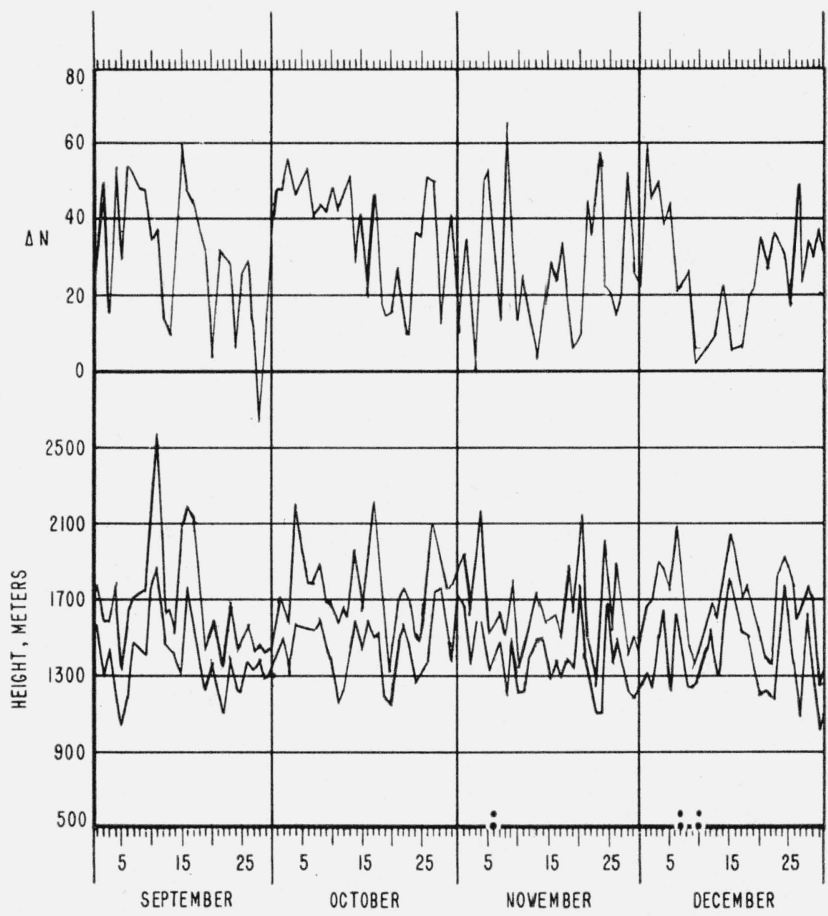

Figure 4. Chronological plots of heights at top and bottom of inversion, and decrease of $N$ through inversion $(\Delta N)$. Ascension Island, midnight soundings, 1957, Double dots at bottom denote 
TABLE 2

\begin{tabular}{|c|c|c|}
\hline Station & Period & Ducts \\
\hline & & $\%$ \\
\hline Ascension I & $\left\{\begin{array}{l}1943 \text { to } 1946 \\
1957 \text { to } 1958\end{array}\right.$ & $\begin{array}{l}21 \\
60\end{array}$ \\
\hline Fernando de Noronha. & $\begin{array}{r}1944 \\
\end{array}$ & 15 \\
\hline $\begin{array}{l}\text { Luanda. } \\
\text { Natal }\end{array}$ & $\begin{array}{l}1957 \text { to } 1958 \\
1943 \text { to } 1946\end{array}$ & $\begin{array}{r}1 \\
14\end{array}$ \\
\hline Recife... & $\left\{\begin{array}{l}1950 \text { to } 1952 \\
1954 \text { to } 1957\end{array}\right.$ & $\begin{array}{r}8 \\
24\end{array}$ \\
\hline
\end{tabular}

ment series show a much larger percentage of ducts present. (In the case of Luanda, which shows a very low percentage, it is known that this station still used the hair hygrometer.)

\subsection{Four-Per-Day Radiosonde Measurements}

The 4-per-day soundings at Fernando de Noronha and Ascension Island were scheduled to explore a possible diurnal trend in inversion height. The analysis of the significant level tabulations for inversion characteristics showed no significant diurnal variation, however.

During the two-week period, six soundings showed no inversion in the significant-level data. Inspection of the recorder charts, which were supplied for this period, showed that a large humidity lapse did occur through the normal levels of the inversion, in spite of no significant temperature change. Furthermore, examination of the charts showed that it was a consistent practice for the observers to smooth the records (in accordance with standard scaling procedures) in such a way as to yield a reduced humidity gradient. As a consequence, indications of the presence of a duct through analysis of significant level tabulations are made pessimistic, even beyond the effect of lag of the temperature and humidity sensing elements discussed earlier.

As a specific illustration, figure 5 shows plots of $M$ versus height for the $1800 \mathrm{GCT}$ sounding of November 30,1958 . At the time of this sounding, by a fortunate coincidence, a refractometer sounding also was taken in the same area by Dr. Cunningham. The dotted line is the plot of the significant level data, while the solid line is the plot of values scaled directly from the radiosonde recorder chart to reveal all the detail contained in the record. Also shown is the plot of the refractometer measurements made by Dr. Cunningham. Although the refractometer sounding shows two duct regions, the plot of the significant levels shows none, while the plot of the values scaled directly from the recorder chart indicates two ducts, each weaker and higher than the corresponding duct indicated by the refractometer plot. Thus this one comparison is in agreement with the general behavior predicted by Andre and mentioned in section 4.1.

\subsection{Airborne Refractometer Measurements}

In view of the rather large number of soundings taken by Dr. Cunningham, only a few samples of these will be included here. One already has been

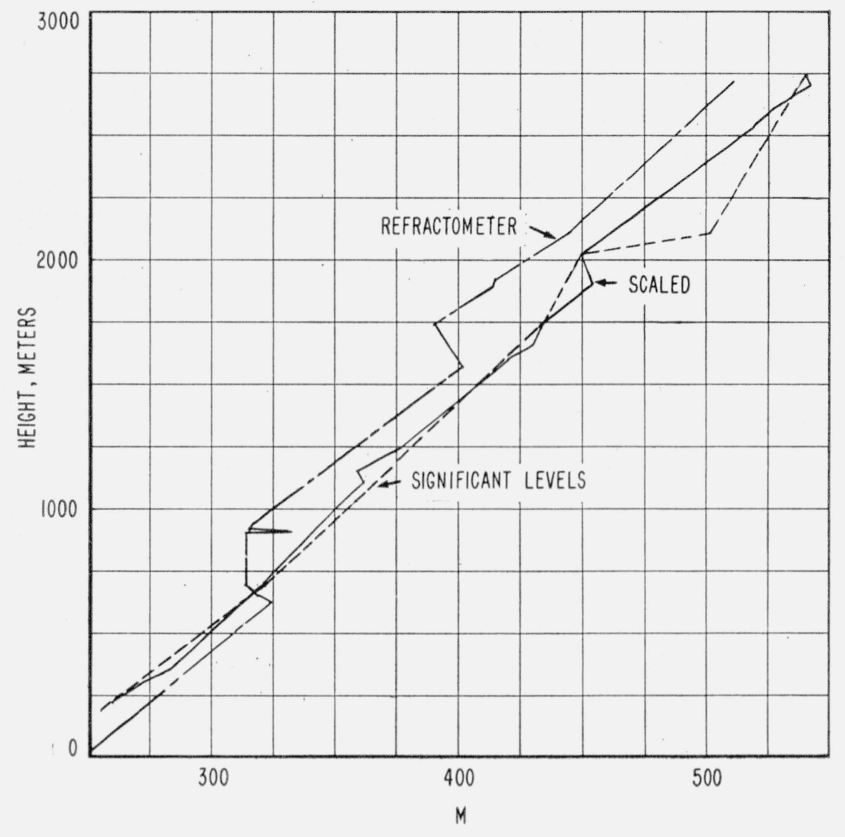

Figure 5. Comparison of radiosonde and refractometer soundings.

Fernando de Noronha, November 30, 1958.

shown in figure 5, and two others are shown in figure 6. The essential data relating to the duct region at the height of the trade-wind inversion for all of the refractometer soundings analyzed are given in table 3 .

The soundings in figure 6 are typical of a number of cases in which the layer was indicated as having a serrated edge. This is due to the fact that the soundings actually are slant sections, however, rather than vertical profiles through the layer. The bottom of the inversion has a wavy profile, so that, at a vertical rate of the aircraft of 500 to 1,000 $\mathrm{ft} / \mathrm{min}$, the aircraft passes through several of the wave crests. This was verified in several horizontal runs through the cloud tops.

Table 3 lists the duct characteristics derived from the $M$-curves plotted for each profile. The table gives values of duct height, and thickness (in meters) and duct strength $(\Delta M)$ for each sounding, and the latitude and longitude corresponding to passage of the aircraft through the inversion. Of 68 soundings tabulated, only one showed no duct present. In two cases there was a gap in the recording because of a scale change made just at the time of passage through the inversion, so that values of duct thickness and strength could not be determined for these, although it was obvious that a duct existed.

Comparison of the aircraft soundings with the data derived from the radiosonde summaries shows that the inversion is much sharper and more intense than the radiosonde indicates. The transition frequently takes place in less than $30 \mathrm{~m}$. As a result, stronger and thicker ducts are shown by the aircraft soundings. 
TABLE 3

\begin{tabular}{|c|c|c|c|c|c|c|}
\hline Date & Run & $h$ & $\Delta h$ & $\Delta M$ & ${ }^{\circ} \mathrm{S}$ & ${ }^{\circ} \mathrm{W}$ \\
\hline $11 / 30 \ldots$ & $\begin{array}{r}2 \\
3 \\
4 \\
5 \\
6 \\
7 \\
8 \\
9 \\
10\end{array}$ & $\begin{array}{l}1650 \\
1655 \\
1450 \\
1370 \\
1460 \\
1130 \\
1740 \\
1570 \\
1585\end{array}$ & $\begin{array}{r}110 \\
110 \\
230 \\
115 \\
200 \\
45 \\
180 \\
70 \\
?\end{array}$ & $\begin{array}{r}19 \\
14 \\
23 \\
10 \\
18 \\
1 \\
9 \\
16 \\
?\end{array}$ & $\begin{array}{l}8.2 \\
8.1 \\
8.1 \\
6.2 \\
5.4 \\
4.3 \\
3.8 \\
6.5 \\
8.0\end{array}$ & $\begin{array}{l}34.7 \\
31.2 \\
31.2 \\
31.7 \\
31.9 \\
32.3 \\
32.4 \\
33.9 \\
34.7\end{array}$ \\
\hline $12 / 1$ & $\begin{array}{r}1 \\
2 \\
3 \\
4 \mathrm{a} \\
4 \mathrm{~b} \\
5 \\
6 \\
7\end{array}$ & $\begin{array}{l}2040 \\
1540 \\
1495 \\
1495 \\
1515 \\
1470 \\
1610 \\
1510\end{array}$ & $\begin{array}{r}? \\
165 \\
130 \\
150 \\
245 \\
280 \\
200 \\
260\end{array}$ & $\begin{array}{r}34 \\
11 \\
8 \\
12 \\
15 \\
18 \\
13 \\
44\end{array}$ & $\begin{array}{l}8.1 \\
8.5 \\
8.3 \\
8.2 \\
8.1 \\
8.0 \\
8.0 \\
8.2\end{array}$ & $\begin{array}{l}34.7 \\
29.5 \\
30.6 \\
31.2 \\
32.1 \\
33.0 \\
34.1 \\
34.5\end{array}$ \\
\hline $12 / 2$ & $\begin{array}{l}2 \\
3 \\
4\end{array}$ & $\begin{array}{l}1695 \\
2050\end{array}$ & $\begin{array}{l}160 \\
200\end{array}$ & $\begin{array}{l}11 \\
29\end{array}$ & $\begin{array}{l}3.7 \\
3.6 \\
6.1\end{array}$ & $\begin{array}{l}32.4 \\
32.5 \\
33.9\end{array}$ \\
\hline & $\begin{array}{l}5 \\
6\end{array}$ & $\begin{array}{l}2050 \\
1670\end{array}$ & $\begin{array}{r}335 \\
90\end{array}$ & $\begin{array}{r}23 \\
6\end{array}$ & $\begin{array}{l}6.7 \\
8.0\end{array}$ & $\begin{array}{l}34.2 \\
34.8\end{array}$ \\
\hline $12 / 5$ & $\begin{array}{l}1 \\
2 \\
3 \\
4\end{array}$ & $\begin{array}{l}1480 \\
1465 \\
1490 \\
1440\end{array}$ & $\begin{array}{r}80 \\
320 \\
315 \\
30\end{array}$ & $\begin{array}{r}5 \\
36 \\
30 \\
9\end{array}$ & $\begin{array}{l}8.2 \\
8.5 \\
8.5 \\
8.0\end{array}$ & $\begin{array}{l}34.2 \\
25.7 \\
23.7 \\
15.8\end{array}$ \\
\hline $12 / 6_{\ldots} \ldots$ & $\begin{array}{l}1 \\
2 \\
3 \\
4 \\
5 \\
6 \\
7 \\
8\end{array}$ & $\begin{array}{l}1305 \\
1445 \\
1500 \\
1405 \\
1285 \\
1450 \\
1485 \\
1440\end{array}$ & $\begin{array}{l}160 \\
245 \\
235 \\
365 \\
170 \\
235 \\
105 \\
235\end{array}$ & $\begin{array}{l}17 \\
19 \\
17 \\
31 \\
16 \\
22 \\
10 \\
27\end{array}$ & $\begin{array}{l}8.2 \\
7.6 \\
7.7 \\
8.0 \\
8.1 \\
8.1 \\
8.1 \\
8.7\end{array}$ & $\begin{array}{l}14.2 \\
20.1 \\
19.4 \\
17.7 \\
17.0 \\
16.1 \\
15.5 \\
14.9\end{array}$ \\
\hline $12 / 7 \ldots$ & $\begin{array}{r}1 \\
2 \\
4 \\
11 \\
12 \\
13 \\
14\end{array}$ & $\begin{array}{l}1680 \\
1270 \\
1280 \\
1470 \\
1380 \\
1570 \\
1680\end{array}$ & $\begin{array}{l}210 \\
525 \\
460 \\
170 \\
260 \\
210 \\
305\end{array}$ & $\begin{array}{l}11 \\
50 \\
34 \\
18 \\
34 \\
13 \\
36\end{array}$ & $\begin{array}{r}8.3 \\
10.8 \\
10.5 \\
8.7 \\
8.7 \\
8.6 \\
8.1\end{array}$ & $\begin{array}{r}14.0 \\
8.9 \\
10.0 \\
12.7 \\
13.0 \\
13.4 \\
14.1\end{array}$ \\
\hline $12 / 8 \ldots$ & $\begin{array}{r}1 \\
2 \\
3 \\
4 \\
5 \\
6 \\
7 \\
8 \\
9 \\
10 \\
11 \\
12 \\
13 \\
14 \\
15 \\
16\end{array}$ & $\begin{array}{l}1300 \\
1410 \\
1380 \\
1435 \\
1375 \\
1430 \\
1390 \\
1350 \\
1320 \\
1485 \\
1455 \\
1505 \\
1580 \\
1430 \\
1410 \\
1485\end{array}$ & $\begin{array}{r}175 \\
410 \\
400 \\
410 \\
150 \\
580 \\
>510 \\
390 \\
430 \\
410 \\
365 \\
320 \\
430 \\
285 \\
125 \\
180\end{array}$ & $\begin{array}{l}21 \\
30 \\
46 \\
27 \\
15 \\
45 \\
50 \\
47 \\
26 \\
44 \\
26 \\
30 \\
34 \\
21 \\
4 \\
11\end{array}$ & $\begin{array}{l}8.0 \\
8.2 \\
8.2 \\
8.2 \\
8.1 \\
8.1 \\
8.1 \\
8.1 \\
8.1 \\
8.0 \\
8.0 \\
7.9 \\
7.9 \\
7.8 \\
7.8 \\
8.0\end{array}$ & $\begin{array}{l}14.3 \\
20.3 \\
19.8 \\
19.5 \\
19.1 \\
18.7 \\
18.3 \\
18.0 \\
17.6 \\
16.8 \\
16.4 \\
16.1 \\
15.7 \\
15.2 \\
14.5 \\
14.5\end{array}$ \\
\hline $12 / 9_{\ldots} \ldots$ & $\begin{array}{l}1 \\
2 \\
3 \\
4 \\
5 \\
6\end{array}$ & $\begin{array}{l}1595 \\
1300 \\
1500 \\
1550 \\
1410 \\
1720\end{array}$ & $\begin{array}{l}105 \\
405 \\
430 \\
255 \\
110 \\
140\end{array}$ & $\begin{array}{r}11 \\
34 \\
32 \\
42 \\
4 \\
10\end{array}$ & $\begin{array}{l}8.0 \\
7.9 \\
8.0 \\
8.2 \\
8.3 \\
8.2\end{array}$ & $\begin{array}{l}14.5 \\
25.3 \\
26.0 \\
26.7 \\
27.5 \\
34.5\end{array}$ \\
\hline $12 / 10 \ldots$ & $\begin{array}{l}10 \\
11 \\
12 \\
13 \\
14\end{array}$ & $\begin{array}{l}1000 \\
1370 \\
1580 \\
1660 \\
1690\end{array}$ & $\begin{array}{r}60 \\
275 \\
90 \\
250 \\
275\end{array}$ & $\begin{array}{l}14 \\
36 \\
30 \\
26 \\
26\end{array}$ & $\begin{array}{l}8.1 \\
7.9 \\
7.9 \\
7.8 \\
8.0\end{array}$ & $\begin{array}{l}32.9 \\
33.1 \\
34.5 \\
34.5 \\
34.6\end{array}$ \\
\hline
\end{tabular}

An approximate method of calculating the critical wavelength for trapping in an elevated duct composed of straight line segments was derived by the phase integral (WKB) method. When applied to the $M$-curves of figure 1 , for example, the results shown in table 4 were obtained.

If it is assumed that the radiosonde underestimates the decrease in $N$ and overestimates the height over which it takes place, then both the thickness of the duct and the magnitude of the decrease in $N$ through it will be underestimated. Hence this will indicate

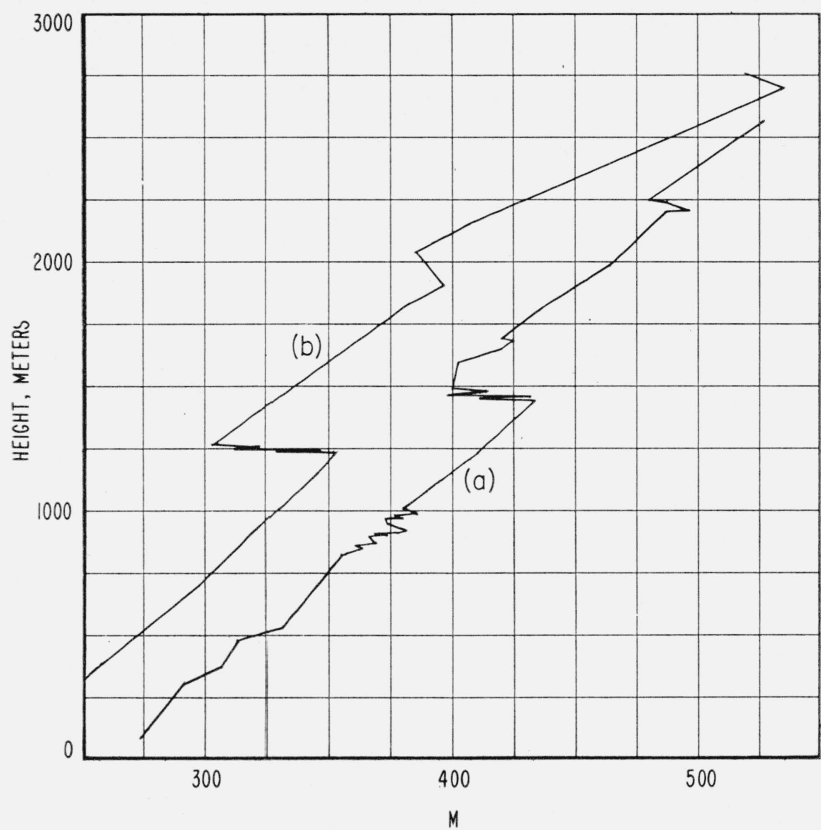

FiguRE 6. M-curves from refractometer soundings.

(a) Taken at $08.5^{\circ} \mathrm{S}, 25.7^{\circ} \mathrm{W}$, December 5,1958 ; (b) taken at $10.8^{\circ} \mathrm{S}, 08.9^{\circ} \mathrm{W}$, December 7,1958

TABLE 4

$\lambda_{\max }($ meters $)$

$f_{\min }(\mathrm{Mc})$

M-curve

\begin{tabular}{|c|c|c|}
\hline & $M-\mathrm{cl}$ & \\
\hline & Fig. 1 & Fig. 9 \\
\hline $\begin{array}{l}\mathrm{ax}(\text { meters }) \\
\text { in }(\mathrm{Mc})\end{array}$ & $\begin{array}{l}3.06 \\
98\end{array}$ & $\begin{array}{l}8.37 \\
37\end{array}$ \\
\hline
\end{tabular}

a smaller trapped wavelength, and thus a higher minimum trapped frequency.

Out of the 68 soundings for which $\Delta M$ could be determined, it was found that only one would have a value of $f_{\min }$ above $200 \mathrm{Mc}$.

\section{Conclusions}

In view of the facts that

(a) the radiosonde consistently underestimates ducting conditions,

(b) the more recent data show ducts present in the majority of the soundings, and

(c) the aircraft soundings show consistently stronger ducts than the radiosonde data,

it is concluded that a duct is probably present most, if not all, of the time. From the observed duct characteristics, it is estimated that a conservative value of minimum trapped frequency is around $200 \mathrm{Mc}$.

An initial experimental test of the trapping capabilities of the trade wind inversion should aim at utilizing the potentialities in an optimum fashion. Thus the waves should be launched in the duct and received in the duct. Otherwise a large loss in exciting the trapped wave in the duct probably would be 
incurred. From the data presented, it can be seen that the duct straddles the lower edge of the inversion. Hence a general guide is to locate the transmitting and receiving antennas just below the base of the inversion. This level generally is easy to determine because the cumulus clouds which are prevalent in the tropics generally terminate at the inversion base. The use of two aircraft for the transmitting and receiving terminals thus is indicated.

With regard to the choice of frequency, the effect of irregularities or "roughness" of the inversion boundaries and occasional "holes" in the inversion along the path must be considered. Roughness of the boundaries will result in a certain amount of scattering out of the duct, which should increase with frequency as the scattering irregularities become larger with respect to the wavelength. A "hole" in the duct will be somewhat equivalent to breaking a waveguide and separating the two parts. The transmitting end of the break will then radiate like a horn antenna and the receiving end will act like a receiving horn. The directivity of these equivalent horns will increase with frequency. Thus, if the axes of the horns are in line, a higher frequency should bridge the gap with lower attenuation than a lower frequency. But if the axes are out of line by an angle comparable to the beamwidth of the equivalent horn antenna, then a large loss will take place between the two ends of the break or hole. In this case a lower frequency would produce less loss. Because of the earth's curvature, an extensive hole in the duct would be equivalent to a misalinement of the axes at the apertures. From this it is concluded that frequencies not too far above the minimum trapped frequency should be used.
In making the final choice of frequency, other mechanisms of propagation which might interfere with or confuse the interpretation of the results should be considered. These mechanisms are meteoric and ionospheric scatter. The effectiveness of these mechanisms decreases rapidly with increasing frequency. At a frequency of $200 \mathrm{Mc}$ these mechanisms should be feeble compared to the duct mechanism, so that such a frequency appears to be a good choice for an initial experiment.

\section{References}

[1] C. S. Durst, Radio climatology, Meteorological factors in radio-wave propagation, pp. 193-212 (Physical Society (London), 1946)

[2] H. v. Ficker, Die Passatinversion, Veroff, d. Met. Inst. d. Univ. Berlin, 1, No. 4 (1936); translation into English by M. Flint, R.T.P. Translation No. 2371.

[3] W. Schnapauff, Untersuchungen Uber die Kalmenzone des Atlantischen Ozeans, Veroff d. Met. Inst. d. Univ. Berlin., 2, No. 4 1937. English translation ASTIA Document No. A.T.I. 113162.

[4] H. Riehl, Tropical Meteorology (McGraw-Hill Book Co., Inc., New York, N.Y., 1954).

[5] E. K. Smith, Jr., and S. Weintraub, Constants in the equation for atmospheric refractive index at radio frequencies, J. Research NBS 50, 39 (1953); Proc. IRE., 41, 1,035 (1953).

[6] M. J. Andre, Limitations of radiosonde data for refractive index computations and note on services available from Air Weather Service, Proceedings of Symposium on Present and Future Uses of Refractive Index Data for Radio Propagation Purposes, Air Force Cambridge Research Center, (Sept. 6-7, 1956).

Boulder, Colo.

(Paper 64D3-54) 